\title{
Calcifying cystic odontogenic tumour manifesting in the maxillary antrum: Case report
}

\author{
Eunice Kihara $^{1}$, Richard Owino ${ }^{2}$, Josiah Otwoma ${ }^{1}$, Elizabeth Dimba ${ }^{1}$, Mark Chindia ${ }^{1}$ \\ ${ }^{1}$ Department of Oral \& Maxillofacial Surgery-Oral Pathology \& Oral Medicine, University of Nairobi, Nairobi, Kenya \\ ${ }^{2}$ Department of Paediatric Dentistry \& Orthodontics, University of Nairobi, Nairobi, Kenya \\ Email: eunik20@yahoo.com
}

Received 31 October 2013; revised 1 December 2013; accepted 12 December 2013

Copyright (c) 2013 Eunice Kihara et al. This is an open access article distributed under the Creative Commons Attribution License, which permits unrestricted use, distribution, and reproduction in any medium, provided the original work is properly cited.

\begin{abstract}
A case is presented of a 15-year-old boy who manifested the calcifying cystic odontogenic tumour (CCOT) in the left maxillary antrum of an unknown duration. In addition, the patient had a high arched palate and multiple impacted teeth of the normal series and supernumerary type including mesiodens as demonstrated in an orthopantomograph.
\end{abstract}

Keywords: Case Reports; Odontogenic Cyst; Calcifying; Odontogenic Tumours; Maxillary Sinus

\section{INTRODUCTION}

Generally, benign odontogenic neoplasms are relatively rare lesions that are derived from either the epithelial and mesenchymal components or the remnant elements of the developing tooth germs. These lesions are often classified according to location as peripheral or central entities [1-4]. In this category of diseases, the calcifying cystic odontogenic tumour (CCOT) is a particularly rare benign entity that is characterized by an ameloblastoma-like epithelium and ghost cells that have the potential to undergo calcification [4-6]. The lesion usually appears as a painless, slow-growing tumour that may involve the maxilla or mandible in the anterior segments $[1,3]$. We report a 15-year-old boy who presented with CCOT manifesting in the left maxillary antrum associated with dental malformation, tooth impaction and a high arched palate.

\section{CASE REPORT}

A 15-year-old boy was referred to our clinic for evaluation and management of a persistent swelling of the left maxilla that had, apparently, been noted nearly two years previously. Over that period, the swelling had been essentially painless. However, the patient reported that the swelling had then become painful. In addition, he also experienced a feeling of stuffiness in the left nostril. The patient's general medical and dental history was unremarkable. On examination, the patient manifested a nontender mass causing facial asymmetry with fullness in the left nasolabial fold extending towards the body of the zygoma. Intraorally, there was total left maxillary sulcular fullness, a mixed dentition and a generalized malpositioning of some teeth in both arches in addition to a high arched palate. A panoramic radiograph revealed multiple bony impacted teeth of the normal series and those of the supernumerary type and mesiodens "Figure 1". The radiograph also demonstrated a remarkably expanded opacified left maxillary sinus.

Under a local anaesthetic, aspiration of the lesion yielded a shimmering amber-coloured cystic fluid. Then an open incisional biopsy was obtained which on histopathological examination demonstrated a fibrous capsule associated with odontogenic cells with low mitotic indices and no pleomorphism. In addition, there were armophous areas of eosinophilic material interspersed within the cells. Ghost cells were prominent "Figure 2". The tumour was, thereafter, totally extirpated under general anaesthesia "Figure 3". The patient remains well after about a 1-year regular follow up.

\section{DISCUSSION}

The most recent WHO classification proposes the diagnostic designations CCOT and dentinogenic ghost cell tumour (DGCT) to differentiate between the cystic and solid lesion [5]. Remarkably, these lesions may occur in association with other odontogenic tumours including, in most instances, the adenomatoid odontogenic tumour [7], ameloblastoma and odontoma [6] and odontogenic keratocystic tumour [8]. Practically, then, obtaining an adequate biopsy specimen that is representative of the entire lesion during histopathological analysis has to be man- 


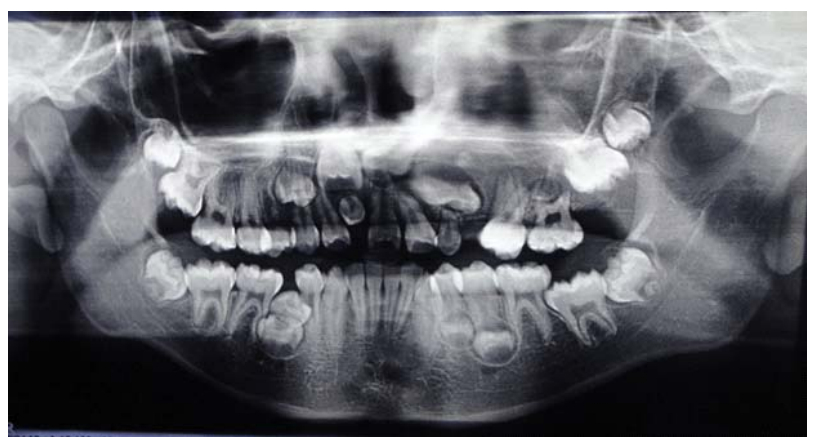

Figure 1. Panoramic view demonstrating an opacified left maxillary antrum, multiple impacted and supernumeraries as well as a calcified mass apical to 23 .

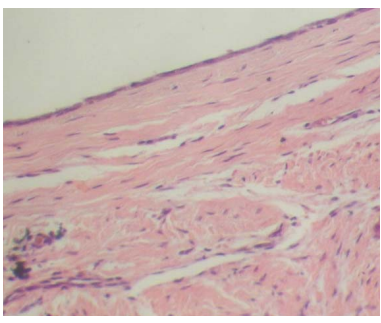

(a)

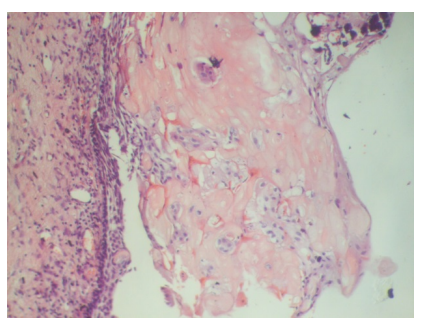

(b)
Figure 2. (a) Thin stratified squamous epithelial lining overlying a fibrous connective tissue stroma; (b) Deposits of eosinophilic material resembling dentin, ghost cell masses without nuclei and areas of calcification ( $\mathrm{H}$ and E sections $100 \times$ ).

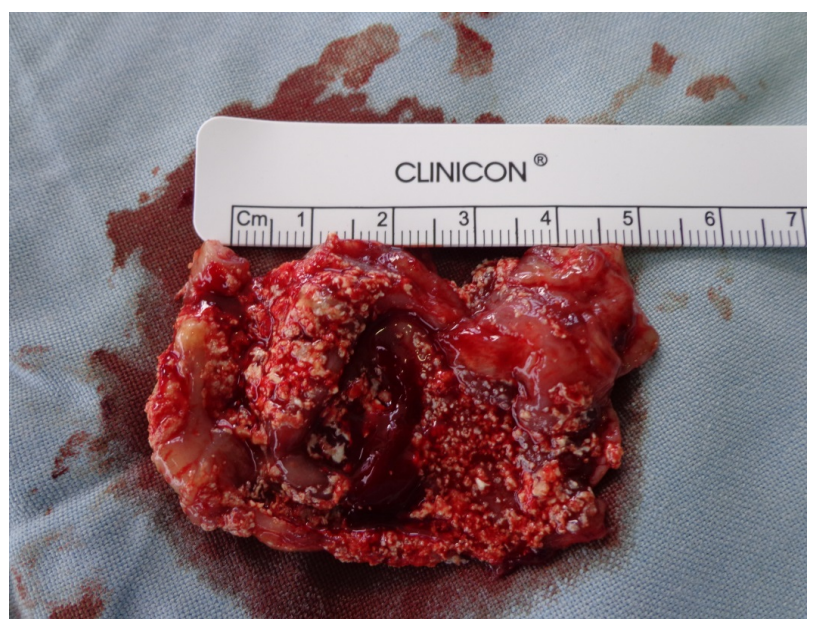

Figure 3. Excised mass showing the thick capsule and white calcific material.

datory. This is because should CCOT occur in association with ameloblastoma, the management modality must conform to that of the letter so that undesirable morbidity is avoided.

As for the present case, the entire lesion was histologically reexamined after it was extirpated. Intraoperatively the main challenge entailed clinically differentiating tumour lining from the normal paranasal lining tissues in some areas. Fortunately, as has been described in the literature $[1,4]$ the cystic lining of the tumour tends to be uniformly thick and, therefore, easy to separate from the normal tissues.

With regard to the demographic pattern of CCOT, it has been reported that the lesion may manifest between the ages of 5 and 75 years with a mean of 25 years [9]. In a 30-year series of 60 CCOT cases [2], a male preponderance was demonstrated (37 male and 23 female). Overall, other than tooth impaction, a few other clinical features have been described such as those in the present case which may imply a syndromic pattern of the tumour on rare occasions.

\section{CONCLUSION}

A 15-year-old male presented with a rare case of a maxillary sinus CCOT which was associated with multiple impacted and supernumerary teeth and a high arched palate. Radiographic and histological examinations were consistent with features of CCOT. The patient remains well after the enucleation of the tumour. Although rare, CCOT is an important clinical entity since it may concomitantly occur with other destructive lesions including ameloblastoma and the keratocystic odontogenic tumour. Clinicians should, therefore, be encouraged to present these cases as they occur.

\section{ACKNOWLEDGEMENTS}

We are most grateful to Pamela Muhonja Kegode for her participation in the management of the patient and Sally Musinde for preparing the manuscript.

\section{REFERENCES}

[1] Johnson III, A., Fletcher, M., Gold, L. and Chen, S.-Y. (1997) Calcifying odontogenic cyst: A clinicopathologic study of 57 cases with Immunohistochemical Evaluation for Cytokeratin. Journal of Oral and Maxillofacial Surgery, 55, 679-683.

http://dx.doi.org/10.1016/S0278-2391(97)90574-7

[2] Habibi, A., Saghravanian, N., Salehinejad, J. and Jafarzadeh, H. (2011) thirty years clinicopathological study of 60 Calcifying cystic odontogenic tumours in Iranian Population. The Journal of Contemporary Dental Practice, 12, 171-173.

[3] Utumi, E.R., Pedron, I.G., Silva, L.P., Machado, G.G. and Rocha, A.C. (2012) Different manifestations of calcifying cystic Odontogenic tumour. Einstein (Sao Paulo), 10, 366-370. http://dx.doi.org/10.1590/S1679-45082012000300019

[4] De Lima, A.P., Kitakawa, D., Almeida, J.D., Brandao, A.A.H. and Anbinder, A.L. (2012) Peripheral calcifying odontogenic tumour of the maxillary gingiva. BMC Research Notes, 5, 455-457.

http://dx.doi.org/10.1186/1756-0500-5-455

[5] Barnes, L., Everson, J.W., Reichert, P.A., et al.; World 
Health Organisation Classification of Tumours (2005) Pathology and genetics of tumours of the head and neck. Chapter 6. Odontogenic tumours. IARC, Lyon, 283-327.

[6] Slootweg, P.J. (2007) Dental pathology: A practical introduction. Springer, Berlin.

[7] Zeitoun, I.M., Dhanrajani, P.J. and Masodomi, H.A. (1996) Adenomatoid odontogenic tumour arising in calcifying Odontogenic cyst. Journal of Oral and Maxillofacial Surgery, 54, 634-637.

http://dx.doi.org/10.1016/S0278-2391(96)90650-3
[8] Basile, J.R., Klene, C. and Lin, Y.L. (2010) Calcifying odontogenic cyst with odontogenic keratocyst: A case report and review of the literature. Oral Surgery, Oral Medicine, Oral Pathology, Oral Radiology and Endodontology, 109, e40-e45.

http://dx.doi.org/10.1016/j.tripleo.2009.12.026

[9] Daniels, J.S.M. (2006) Recurrent calcifying odontogenic cyst involving the maxillary sinus. Oral Surgery, Oral Medicine, Oral Pathology, Oral Radiology and Endodontology, 101, 356-362. 